\title{
OPTIMALISASI BIAYA TRANSPORTASI PENDISTRIBUSIAN KERAMIK MENGGUNAKAN MODEL TRANSPORTASI METODE MODIFIED DISTRIBUSITION(STUDI KASUS : PT. INDAH BANGUNAN)
}

\author{
S. Ayulinansyah ${ }^{1}$, A. I. Jaya², dan A. Sahari ${ }^{3}$ \\ 1,2,3 Program Studi Matematika Jurusan Matematika \\ Fakultas Matematika dan IImu Pengetahuan Alam Universitas Tadulako \\ Jalan Sukarno-Hatta Km. 9 Palu 94118, Indonesia \\ 1Sri_ayulinansyah@yahoo.com, 2jayaindraagus@gmail.com,3Agusman_sh@yahoo.com
}

\begin{abstract}
This study was conducted to obtain optimal costs of transportation in the distribution of Ceramics at PT. Indah Bangunan Palu. This research is carried out by several steps such as: making the model transportation of obtained the data, determining the initial solution by the method of Least cost, and finding the optimal solution with Modified Distribution (MODI) method. The research results showed that an initial solution is $R p .53 .919 .000$ and the optimal solution is $R p .53 .756 .000$. On the other hand the transportation cost from the company before optimization is Rp. 62.126.000. This indicates that PT. Indah Bangunan Palu can optimize the costs of transport for the distribution of ceramics on September 2016 with a cost savings of $R p .8 .370 .000$ or $13 \%$.
\end{abstract}

Keywords $\quad$ : Least Cost Method, Modified Method of Distribution, Optimization, Transportation

\begin{abstract}
ABSTRAK
Penelitian ini bertujuan untuk memperoleh biaya transportasi yang optimal dalam pendistribusian Keramik pada PT. Indah Bangunan Palu. Penelitian ini dilaksanakan dalam beberapa langkah yaitu: dengan membuat model transportasi dari data yang diperoleh, menentukan solusi awal dengan metode Least Cost, dan mendapatkan solusi optimal dengan metode Modified Distribution (MOD). Dari hasil penelitian didapatkan solusi awal sebesar $R p .53 .919 .000$ dan solusi optimal sebesar $R p$.53.756.000. Sedangkan biaya transportasi dari perusahaan sebelum dilakukan pengoptimalan sebesar Rp.62.126.000. Hal ini menunjukkan bahwa PT. Indah Bangunan Palu dapat mengoptimalkan biaya transportasi untuk pendistribusian keramik pada bulan September 2016 dengan penghematan biaya sebesar $R p .8 .370 .000$ atau $13 \%$.
\end{abstract}

Kata Kunci : : Metode Least Cost, Metode Modified Distribution, Optimalisasi, Transportasi 


\section{PENDAHULUAN}

\subsection{Latar Belakang}

Secara umum, setiap perusahaan akan mengalami masalah dalam hal pendistribusian barang, disamping itu perusahaan juga dituntut untuk dapat memenuhi kebutuhan pelanggan serta dapat mempertahankan tingkat kepuasan dari Pelanggannya. Penurunan tingkat kepuasan pelanggan dapat mengakibatkan penurunan kepercayaan pelanggan, bahkan dapat pula menyebabkan hilangnya pelanggan perusahaan tersebut supaya hal ini tidak terjadi, perusahaan perlu melakukan analisa faktor-faktor penentu tingkat kepuasan pelanggan (Sutapa, 2007).

Setiap perusahaan di dunia selalu mengharapkan ke untungan yang semaksimal mungkin agar siklus hidup perusahaan berjalan. Untuk itu perusahaan tersebut mampu mengatur sedemikian rupa biaya yang harus digunakan agar tetap terjadi rentang antara pengeluaran dan pemasukan perusahaan. Semakin besar rentang antara pemasukan dan pengeluaran perusahaan maka semakin besar pula keuntungan yang akan diperoleh dengan harapan pengeluaran selalu lebih rendah dari pada pemasukan perusahaan.

Salah satu faktor yang menentukan tingkat kepuasan pelanggan adalah biaya distribusi yang optimal oleh perusahaan kepada pelanggan. Untuk mengantisipasi hal ini, maka harus direncanakan suatu model transportasi yang sesuai dan dapat diterapkan kapan saja. Tujuan dari model transportasi ini adalah menentukan jumlah barang yang harus dikirimkan dari setiap sumber ke setiap tujuan sedemikian rupa sehingga biaya transportasi total minimum (Taha, 1996).

Perusahaan distribusi merupakan suatu perusahaan yang membeli barang dari produsen (pembuat barang langsung) dan kemudian menjual kembali barang tersebut untuk memperoleh laba, PT. Indah Bangunan salah satu perusahaan yang mendistribusikan produk bangunan yang terletak di Provinsi Sulawesi Tengah. PT. Indah Bangunan yang didirikan pada tahun 2008 oleh Bapak Harto B, SE yang berlokasi di Jln. Adam Malik Provinsi Sulawesi Tengah Palu, melayani permintaan para agen pendistribusian bahan banguanan (keramik). Layanan ini dibatasi oleh kapasitas gudang dari masing-masing agen dan toko tujuan agen. Dalam hal pendistribusian, untuk biaya transportasi total biaya minimum dalam pengalokasian bahan bangunan kepada beberapa toko tujuan agen masih menjadi masalah bagi perusahaan.

Oleh karena itu, PT. Indah Bangunan membutuhkan metode yang tepat agar produk tersebut dapat didistribusikan dari beberapa agen (sumber) ke beberapa konsumen (tujuan) sehingga menghasilkan biaya transportasi minimum. Untuk pemecahan solusi ini, maka dapat diterapkan Metode Least Cost untuk mendapatkan solusi awal dan Metode Modified 
Distribution (MODI) untuk mencari solusi Optiamal, metode ini diharapkan dapat memberikan solusi untuk mendapatkan biaya transportasi yang optimal.

Berdasarkan latar belakang tersebut, penulis coba menuangkan masalah ini kedalam sebuah tugas akhir yang berjudul : "Optimalisasi Biaya Transportasi Pendistribusian Keramik pada PT. Indah bangunan Palu Menggunakan Model Transportasi Metode Modified Distribution (MOD).

\subsection{Tujuan}

Adapun tujuan yang ingin dicapai dalam penelitian ini adalah Untuk memperoleh biaya transportasi yang optimal dalam pendistribusian keramik di Kota Palu dengan menggunakan model Transportasi metode Modified Distribution (MODI) pada PT. Indah Bangunan.

\subsection{Batasan Masalah}

Adapun asumsi yang digunakan dalam penelitian ini adalah:

1. Wilayah yang menjadi jangkauan pendistribusian bahan bangunan (keramik) pada PT. Indah Bangunan adalah Kota Palu.

2. Dalam penelitian ini, agen-agen pada gudang PT. Indah Bangunan di asumsikan sebagai sumber, dan toko-toko menjadi pelanggan sebagai tujuan.

3. Jumlah sumber yang diteliti ada 3 sumber dan 10 tujuan.

\section{METODE PENELITIAN}

Penelitian dilakukan sesuai prosedur dibawah ini :

1. Mulai penelitian

2. Studi literatur dengan mengumpulkan materi dari buku, artikel dan jurnal

3. Pengambilan data

4. Membuat Matriks Masalah Transportasi

5. Menentukan masalah transportasi dari berbagai sumber dan berbagi tujuan

6. Penerapan metode Least Cost pada masalah transportasi

7. Menentukan solusi optimal dari Metode Modified Distribution

8. Kesimpulan

9. Selesai

\section{HASIL DAN PEMBAHASAN}

\subsection{Hasil penelitian}

Pendistribusian keramik pada PT. Indah Bangunan Palu dilakukan melalui tiga agen. Adapun data persediaan, permintaan, penawaran dan biaya transportasi dari agen ke masingmasing toko adalah sebagai berikut : 
Tabel 1 : Persediaan keramik PT. Indah Bangunan di tiga cabang pada bulan September 2016

\begin{tabular}{|l|l|l|l|}
\hline No. & $\begin{array}{l}\text { Nama } \\
\text { Agen }\end{array}$ & \multicolumn{1}{|c|}{ Alamat } & Persediaan \\
\hline 1 & Agen 1 & Jl. Pelita Air Permai & 2520 dos \\
\hline 2 & Agen 2 & Jl. Rajamoili & 1497 dos \\
\hline 3 & Agen 3 & Jl. Soekarno Hatta & 983 dos \\
\hline \multicolumn{3}{|c|}{ Jumlah } & 5000 dos \\
\hline
\end{tabular}

(sumber: PT. Indah Bangunan Palu)

Adapun data permintaan dari masing-masing toko pelanggan tersebut dapat dilihat pada tabel berikut :

Tabel 2 : Permintaan Pelanggan keramik pada bulan September 2016

\begin{tabular}{|c|l|l|l|}
\hline No. & Pelanggan & Alamat & Permintaan \\
\hline 1 & Toko Sinar Prima $\left(T_{1}\right)$ & Jl.Imam Bonjol & 540 dos \\
\hline 2 & Toko Adil $\left(T_{2}\right)$ & Jl. Basuki Rahmat & 635 dos \\
\hline 3 & Toko Sujaya $\left(T_{3}\right)$ & Jl. Emi Saelan & 520 dos \\
\hline 4 & Toko Agung $\left(T_{4}\right)$ & Jl. Touwa & 570 dos \\
\hline 5 & Toko Usaha Jaya $\left(T_{5}\right)$ & Jl. Raden Saleh & 440 dos \\
\hline 6 & Toko Showroom Keramik $\left(T_{6}\right)$ & Jl. Yosudarso & 425 dos \\
\hline 7 & Toko Aneka Maju $\left(T_{7}\right)$ & Jl. Dewi Sartika & 590 dos \\
\hline 8 & Toko Cahaya Prima $\left(T_{8}\right)$ & Jl. Veteran & 400 dos \\
\hline 9 & Toko Mulia $\left(T_{9}\right)$ & Jl. RE Martadinata & 420 dos \\
\hline 10 & Toko Prima Bangunan $\left(T_{10}\right)$ & Jl. Soeprapto & 460 dos \\
\hline \multicolumn{4}{|c|}{ Jumlah } \\
\hline
\end{tabular}

(sumber: PT. Indah Bangunan Palu)

Data penawaran keramik kesepuluh toko dari masing-masing agen dapat dilihat pada tabel berikut :

Tabel 3 : Penawaran keramik kesepuluh toko dari masing-masing agen pada bulan

September 2016

\begin{tabular}{|c|c|c|c|c|c|}
\hline No. & Toko & $\begin{array}{c}\text { agen 1 } \\
\left(S_{1}\right)\end{array}$ & $\begin{array}{c}\text { agen 2 } \\
\left(S_{2}\right)\end{array}$ & $\begin{array}{c}\text { agen 3 } \\
\left(S_{3}\right)\end{array}$ & $\begin{array}{c}\text { Total } \\
\text { Permintaan }\end{array}$ \\
\hline 1 & $T_{1}$ & 200 & 185 & 155 & 540 \\
\hline 2 & $T_{2}$ & 270 & 185 & 180 & 635 \\
\hline 3 & $T_{3}$ & 210 & 150 & 160 & 520 \\
\hline 4 & $T_{4}$ & 250 & 175 & 145 & 570 \\
\hline 5 & $T_{5}$ & 290 & 75 & 75 & 440 \\
\hline 6 & $T_{6}$ & 280 & 100 & 45 & 425 \\
\hline
\end{tabular}




\begin{tabular}{|c|c|c|c|c|c|}
\hline 7 & $T_{7}$ & 255 & 277 & 58 & 590 \\
\hline 8 & $T_{8}$ & 200 & 150 & 50 & 400 \\
\hline 9 & $T_{9}$ & 285 & 100 & 35 & 420 \\
\hline 10 & $T_{10}$ & 280 & 100 & 80 & 460 \\
\hline
\end{tabular}

(sumber: PT. Indah Bangunan Palu)

Data biaya transportasi pendistribusian produk keramik untuk setiap unit dari agen menuju masing-masing pelanggan dapat dilihat pada tabel berikut:

Tabel 4 : Biaya Transportasi Setiap Pengiriman Produk Keramik dari Agen Menuju Masingmasing Pelanggan pada bulan September 2016

\begin{tabular}{|c|c|c|c|c|c|c|c|c|c|c|}
\hline Dari & $\begin{array}{c}\text { Toko } \\
1 \\
\text { (Rp) }\end{array}$ & $\begin{array}{c}\text { Toko } \\
2 \\
(\mathrm{Rp}) \\
\end{array}$ & $\begin{array}{c}\text { Toko } \\
3 \\
\text { (Rp) }\end{array}$ & $\begin{array}{c}\text { Toko } \\
4 \\
\text { (Rp) }\end{array}$ & $\begin{array}{c}\text { Toko } \\
5 \\
\text { (Rp) }\end{array}$ & $\begin{array}{c}\text { Toko } \\
6 \\
\text { (Rp) }\end{array}$ & $\begin{array}{c}\text { Toko } \\
7 \\
\text { (Rp) }\end{array}$ & $\begin{array}{c}\text { Toko } \\
8 \\
\text { (Rp) }\end{array}$ & $\begin{array}{c}\text { Toko } \\
9 \\
\text { (Rp) }\end{array}$ & $\begin{array}{c}\text { Toko } \\
10 \\
\text { (Rp) }\end{array}$ \\
\hline 1 & $\begin{array}{c}13 . \\
000\end{array}$ & $\begin{array}{c}10 . \\
000\end{array}$ & $\begin{array}{c}11 . \\
000\end{array}$ & $\begin{array}{c}10 . \\
000\end{array}$ & $\begin{array}{c}13 . \\
000\end{array}$ & $\begin{array}{c}12 . \\
000\end{array}$ & $\begin{array}{c}10 . \\
000\end{array}$ & $\begin{array}{c}13 . \\
000\end{array}$ & $\begin{array}{c}15 . \\
000\end{array}$ & $\begin{array}{c}12 . \\
000\end{array}$ \\
\hline $\begin{array}{c}\text { Ager } \\
2\end{array}$ & 000 & $\begin{array}{c}13 . \\
000\end{array}$ & $\begin{array}{c}12 . \\
000\end{array}$ & $\begin{array}{c}13 . \\
000\end{array}$ & $\begin{array}{c}10 . \\
000\end{array}$ & $\begin{array}{c}11 . \\
000\end{array}$ & $\begin{array}{c}13 . \\
000\end{array}$ & $\begin{array}{c}14 . \\
000\end{array}$ & $\begin{array}{c}12 . \\
000\end{array}$ & $\begin{array}{c}10 . \\
000 \\
\end{array}$ \\
\hline $\begin{array}{c}\text { Agen } \\
3 \\
\end{array}$ & $\begin{array}{c}15 . \\
000 \\
\end{array}$ & $\begin{array}{l}14 . \\
000\end{array}$ & $\begin{array}{c}14 . \\
000\end{array}$ & $\begin{array}{c}15 . \\
000 \\
\end{array}$ & $\begin{array}{c}13 . \\
000\end{array}$ & $\begin{array}{c}13 . \\
000\end{array}$ & $\begin{array}{c}15 . \\
000 \\
\end{array}$ & $\begin{array}{c}13 . \\
000\end{array}$ & $\begin{array}{c}10 . \\
000\end{array}$ & $\begin{array}{c}12 . \\
000\end{array}$ \\
\hline
\end{tabular}

(sumber: PT. Indah Bangunan Palu)

Dari seluruh data yang diperoleh akan dibuat matriks model transportasi dapat dilihat pada tabel berikut:

Tabel 5 : Matriks Model Transportasi

\begin{tabular}{|c|c|c|c|c|c|c|c|c|c|c|c|}
\hline Darh & $T_{1}$ & $T_{2}$ & $T_{3}$ & $T_{4}$ & $T_{5}$ & $T_{6}$ & $T_{7}$ & $T_{8}$ & $T_{9}$ & $T_{10}$ & $\begin{array}{l}\text { Pena } \\
\text { waran } \\
\left(S_{i}\right)\end{array}$ \\
\hline \multirow{2}{*}{$\left(S_{1}\right)$} & 13 & 10 & 11 & 10 & 13 & 12 & 10 & 13 & 15 & 12 & \multirow[t]{2}{*}{2520} \\
\hline & $X_{11}$ & $X_{12}$ & $X_{13}$ & $X_{14}$ & $X_{15}$ & $X_{16}$ & $X_{17}$ & $X_{18}$ & $X_{19}$ & $X_{110}$ & \\
\hline \multirow{2}{*}{$\left(S_{2}\right)$} & 12 & 13 & 12 & 13 & 10 & 11 & 13 & 14 & 12 & 10 & \multirow[t]{2}{*}{1497} \\
\hline & $X_{21}$ & $X_{22}$ & $X_{23}$ & $X_{24}$ & $X_{25}$ & $X_{26}$ & $X_{27}$ & $X_{28}$ & $X_{29}$ & $X_{210}$ & \\
\hline \multirow{2}{*}{$\left(S_{3}\right)$} & 15 & 14 & 14 & 15 & 13 & 13 & 15 & 13 & 10 & 12 & \multirow[t]{2}{*}{983} \\
\hline & $X_{31}$ & $X_{32}$ & $X_{33}$ & $X_{34}$ & $X_{35}$ & $X_{36}$ & $X_{37}$ & $X_{38}$ & $X_{39}$ & $X_{3.10}$ & \\
\hline $\begin{array}{l}\text { Permint } \\
\text { aan } \\
\quad\left(P_{j}\right)\end{array}$ & 540 & 635 & 520 & 570 & 440 & 425 & 590 & 400 & 420 & 460 & 5000 \\
\hline
\end{tabular}


Dari tabel model transportasi diatas, akan diformulasiakan model program liniernya sebagai berikut :

\section{Meminimumkan}

$$
\begin{aligned}
& F=\sum_{i=1}^{m} \sum_{j=1}^{n} c_{i j} \cdot x_{i j} \\
& F=13000 X_{11}+10000 X_{12}+11000 X_{13}+10000 X_{14} 13000 X_{15}+12000 X_{16}+10000 X_{17}+ \\
& 13000 X_{18}+15000 X_{19}+12000 X_{1.10}+12000 X_{21}+13000 X_{22}+12000 X_{23}+ \\
& 13000 X_{24}+10000 X_{25}+11000 X_{26}+13000 X_{27}+14000 X_{28}+12000 X_{29}+10000 X_{2.10}+ \\
& 15000 X_{31}+14000 X_{32}+14000 X_{33}+15000 X_{34}+13000 X_{35}+13000 X_{36}+15000 X_{37}+ \\
& 13000 X_{38}+10000 X_{39}+12000 X_{3.10}
\end{aligned}
$$

Dengan batasan :

$\sum_{i=1}^{m} x_{i j}=S_{i}$

$X_{11}+X_{12}+X_{13}+X_{14}+X_{15}+X_{16}+X_{17}+X_{18}+X_{19}+X_{1.10} \leq 1497$

$$
\begin{gathered}
X_{21}+X_{22}+X_{23}+X_{24}+X_{25}+X_{26}+X_{27}+X_{28}+X_{29}+X_{2.10} \leq 1497 \\
X_{31}+X_{32}+X_{33}+X_{34}+X_{35}+X_{36}+X_{37}+X_{38}+X_{39}+X_{3.10} \leq 983
\end{gathered}
$$

$\sum_{j=1}^{n} x_{i j}=P_{i}$

$X_{11}+X_{12}+X_{13} \geq 540$

$X_{12}+X_{22}+X_{32} \geq 635$

$X_{13}+X_{23}+X_{33} \geq 520$

$X_{14}+X_{24}+X_{34} \geq 570$

$X_{15}+X_{25}+X_{35} \geq 440$

$X_{16}+X_{26}+X_{36} \geq 425$

\begin{tabular}{|c|c|c|c|c|c|c|c|c|c|c|c|}
\hline Dehi & $T_{1}$ & $T_{2}$ & $T_{3}$ & $T_{4}$ & $T_{5}$ & $T_{6}$ & $T_{7}$ & $T_{8}$ & $T_{9}$ & $T_{10}$ & $\left(S_{i}\right)$ \\
\hline \multirow{2}{*}{$\left(S_{1}\right)$} & 13 & 10 & 11 & 10 & 13 & 12 & 10 & 13 & 15 & 12 & \multirow[t]{2}{*}{2520} \\
\hline & 205 & 635 & 520 & 670 & & & 590 & & & & \\
\hline \multirow{2}{*}{$\left(S_{2}\right)$} & 12 & 13 & 12 & 13 & 10 & 11 & 13 & 14 & 12 & 10 & \multirow[t]{2}{*}{1497} \\
\hline & 127 & & & & 440 & 425 & & & & 460 & \\
\hline
\end{tabular}

$X_{17}+X_{27}+X_{37} \geq 590$

$X_{18}+X_{28}+X_{38} \geq 400$

$X_{19}+X_{29}+X_{39} \geq 420$

$X_{1.10}+X_{2.10}+X_{3.10} \geq 460$

Selanjutnya dari data yang telah diperoleh akan dicari solusi awalnya dengan menggunakan metode ongkos terkecil (Least Cost)

Tabel 6 : Tabel Solusi Awal Masalah Transportasi 


\begin{tabular}{|l||c||c||c|c||c||c||c||c||c||c||c|}
\hline \multirow{3}{*}{$\left(S_{3}\right)$} & 15 & 14 & 14 & 15 & 13 & 13 & 15 & 13 & 10 & 12 & 983 \\
\cline { 2 - 11 } & 163 & & & & & & & 400 & 420 & & \\
\hline$\left(P_{j}\right)$ & 540 & 635 & 520 & 570 & 440 & 425 & 590 & 400 & 420 & 460 & 5000 \\
\hline
\end{tabular}

Dari tabel 6 diatas dapat diketahui biaya total transportasi pendistribusian keramik sebagai berikut :

$$
\begin{aligned}
F= & 205\left(X_{11}\right)+635\left(X_{12}\right)+520\left(X_{13}\right)+570\left(X_{14}\right)+590\left(X_{17}\right)+172\left(X_{21}\right)+440\left(X_{25}\right)+ \\
& 425\left(X_{26}\right)+460\left(X_{2.10}\right)+163\left(X_{31}\right)+400\left(X_{38}\right)+420\left(X_{39}\right) \\
= & 205(13000)+635(10000)+520(11000)+570(10000)+ \\
& 590(10000)+172(12000)+440(10000)+425(11000)+ \\
& 460(10000)+163(15000)+400(13000)+420(10000) \\
= & 53.919 .000
\end{aligned}
$$

Dari hasil diatas dapat disimpulkan solusi awal biaya transportasi pendistribusian keramik menggunakan metode Least Cost sebesar Rp. 53.919 .000 perbulan. Untuk

\begin{tabular}{|c|c|c|c|c|c|c|c|c|c|c|c|c|}
\hline$K_{j}$ & & $K_{1}$ & $K_{2}$ & $K_{3}$ & $K_{4}$ & $K_{5}$ & $K_{6}$ & $K_{7}$ & $K_{8}$ & $K_{9}$ & $K_{10}$ & \\
\hline & Dakj & $T_{1}$ & $T_{2}$ & $T_{3}$ & $T_{4}$ & $T_{5}$ & $T_{6}$ & $T_{7}$ & $T_{8}$ & $T_{9}$ & $T_{10}$ & $\begin{array}{l}\text { Penaw } \\
\text { aran } \\
\qquad\left(S_{i}\right)\end{array}$ \\
\hline \multirow{2}{*}{$\begin{array}{c}R_{1} \\
0\end{array}$} & \multirow{2}{*}{$\left(S_{1}\right)$} & 13 & 10 & 11 & 10 & 13 & 12 & 10 & 13 & 15 & 12 & \multirow[t]{2}{*}{2520} \\
\hline & & 205 & 635 & 520 & 570 & & & 590 & & & & \\
\hline \multirow[t]{2}{*}{$\begin{array}{l}R_{2} \\
-1\end{array}$} & \multirow{2}{*}{$\left(S_{2}\right)$} & 12 & 13 & 12 & 13 & 10 & 11 & 13 & 14 & 12 & 10 & \multirow[t]{2}{*}{1497} \\
\hline & & 335 & & & & 440 & 262 & & & & 460 & \\
\hline \multirow[t]{2}{*}{$\begin{array}{c}R_{3} \\
1\end{array}$} & \multirow{2}{*}{$\left(S_{3}\right)$} & 15 & 14 & 14 & 15 & 13 & 13 & 15 & 13 & 10 & 12 & \multirow[t]{2}{*}{983} \\
\hline & & & & & & & 163 & & 400 & 420 & & \\
\hline \multicolumn{2}{|c|}{$\begin{array}{l}\text { Perminta } \\
\text { an } \\
\quad\left(P_{j}\right)\end{array}$} & 540 & 635 & 520 & 570 & 440 & 425 & 590 & 400 & 420 & 460 & 5000 \\
\hline
\end{tabular}
memperoleh biaya transportasi yang optimal (biaya murah) pendstribusian produk keramik, langkah selanjutnya akan dikerjakan dengan metode MODI. Setelah dilakukan langkahlangkah dalam menentukan solusi optimal didapatkan biaya transportasi optimal sebagai berikut :

Tabel 7 : Biaya Transportasi yang Optimal 


$$
\begin{aligned}
\text { Biaya transportasi optimal }= & 205(13000)+635(10000)+520(11000)+ \\
& 570(10000)+590(10000)+335(12000)+ \\
& 440(10000)+425(11000)+460(10000)+ \\
& 163(13000)+400(13000)+420(10000) \\
= & 53.756 .00
\end{aligned}
$$

\subsection{Pembahasan}

Pendistribusian keramik pada PT. Indah Bangunan Palu dilakukan melalui tiga agen dengan persediaan keramik ketiga agen yaitu Agen 1 sejumlah 2520 dos, Agen 2 sejumlah 1497 dos, Agen 3 sejumlah 983 dos, masing-masing agen tersebut harus mendistribusikan hasil produknya kepada sepuluh toko yang merupakan pelanggan dari ketiga agen jumlah permintaan dari masing-masing toko pelanggan keramik pada bulan September 2016 yaitu $T_{1}=540, T_{2}=635, T_{3}=520, T_{4}=570, T_{5}=440, T_{6}=425, T_{7}=590, T_{8}=400, T_{9}=425, T_{10}=460$ dengan biaya transportasi yang bebeda-beda disesuaikan dengan jarak setiap kali pengiriman dengan total biaya transportasi untuk pendistribusian keramik dari ketiga agen distributor menuju kesepuluh toko pelanggan pada PT. Indah Bangunan Palu sebesar Rp. 62.126 .000 perbulan. Untuk mendapatkan biaya transportasi pendistribusian keramik yang optimal dilakukan perhitungan menggunakan model transportasi metode $M O D I$, karena indeks perbaikan tidak ada yang bernilai negatif tabel transportasi tidak memungkinkan untuk dimodifikasi lagi.

Tabel 7 merupakan tabel pemecahan optimal pendistribusian keramik kesepuluh toko tujuan, yaitu : Toko Sinar Prima $\left(T_{1}\right)$, Toko Adil $\left(T_{2}\right)$, Toko Sujaya $\left(T_{3}\right)$, Toko Agung $\left(T_{4}\right)$, Toko Usaha Jaya $\left(T_{5}\right)$, Toko Showroom Keramik $\left(T_{6}\right)$, Toko Aneka Maju $\left(T_{7}\right)$, Toko Cahaya Prima $\left(T_{8}\right)$, Toko Mulia $\left(T_{9}\right)$, Toko Prima Bangunan $\left(T_{10}\right)$ dimana jumlah permintaan dan penawaran telah terpenuhi sebanyak 5000 dos. Agen 1 mendistribusikan keramik kelima toko tujuan, yaitu $\left(T_{1}, T_{2}, T_{3}, T_{4}\right.$, dan $\left.T_{7}\right)$, agen 2 mendistribusikan keramik keempat toko tujuan, yaitu $\left(T_{1}, T_{5}\right.$, $T_{6}$, dan $\left.T_{10}\right)$, dan agen 3 mendistribusikan keramik ketiga toko tujuan $\left(T_{6}, T_{8}\right.$, dan $\left.T_{9}\right)$, dengan total biaya transportasi $R p .53 .756 .000$ per bulan.

Pada Tabel 3 dapat disimpulkan bahwa terdapat perbedaan dalam mendistribusikan barang oleh agen. Distribusi sebelum menggunakan metode transportasi yang ditinjaukan tabel 3 memperlihatkan tiga agen mendistribusiakn barang keseluruh toko tujuan dengan dengan total biaya distribusi sebesar $R p .62 .126 .000$, sementara metode transportasi menghasilkan pola distribusi oleh setiap agen ke beberapa toko saja dengan biaya oprasional mencapai Rp.53.756.000. Hal ini menunjukan bahwa metode transportasi mampu memberikan solusi biaya yang minimum dalam upaya menekan biaya distribusi, dimana pada kasus ini mampu menghemat biaya hingga $R p$. 8.370.000 per bulan. 


\section{KESIMPULAN}

Berdasarkan hasil dan pembahasan yang telah dilakukan, dapat disimpulkan bahwa biaya transportasi pendistribusian keramik pada PT. Indah Bangunan pada bulan September 2016 dengan model Transportasi metode Modified Distribution (MODI) di peroleh biaya transportasi optimal yaitu sebesar Rp.53.756.000 perbulan. Sedangkan biaya transportasi sebelum pengoptimalan dari perusahaan yaitu sebesar Rp.62.126.000 perbulan. Hal ini menunjukan bahwa PT. Indah Bangunan dapat mengoptimalkan biaya transportasi untuk pendistribusian produk keramik pada bulan September 2016, dengan penghematan biaya pendistribusian sebesar $R p .8 .370 .000$ atau $13 \%$ per bulan.

\section{DAFTAR PUSTAKA}

[1] . Aminudin, Prinsip-prinsip riset operasi, Erlangga, 2005, Jakarta.

[2]. Nirwansyah, H., dan Widowati, (Seminar Nasional aplikasi sains dan Matematika Dalam Industri), Efesiensi Biaya Distribusi Dengan Metode Transportasi, Jurusan Matematika FMIPA UNDIP, 2007, Semarang.

[3]. Prawirosentono, S., Riset Operasi dan Ekonofisika, Bumi Askara, 2005, Jakarta.

[4]. Sitinjak., dan Tumpal, J. R., Riset Operasi untuk pengambilan keputusan Manajerial dengan aplikasi Exel, Graha IImu, 2006, Yogyakarta.

[5]. Supranto, J., Linier Prograning, Fakultas Ekonomi Universitas Indonesia, 1980, Jakarta.

[6]. Sutapa, N., Desain Rute dan Penjadwalan kendaraan distribusi Air Mineral wilayah Surabaya, 2007, diakses 23 agustus 2016.

[7]. Taha, H. A.., Riset Operasi, Birorupa, Aksara, 1996, Jakarta Barat. 